\title{
Supressão da murcha de fusário em tomateiro por rizobactérias do gênero Bacillus ${ }^{1}$
}

\author{
Renato Carrer Filho ${ }^{2}$, Érico de Campos Dianese ${ }^{2}$, Marcos Gomes da Cunha ${ }^{2}$
}

\begin{abstract}
Suppression of Fusarium wilt in tomato plants by rhizobacteria from the Bacillus genus

Vascular wilting in tomato plants constitutes an important group of diseases incited by soil inhabiting pathogens, especially Fusarium oxysporum f. sp. lycopersici, that causes significant production losses. The introgression of genes that express specific resistance is considered the main control method, however, due to the rapid emergence of races that suppress resistance, biocontrol has been presented as an option to be integrated with genetic control methods. This study aimed at evaluating the ability of rhizobacteria isolates, especially from the Bacillus genus, as biological control agents of Fusarium wilt in tomato plants. The laboratory assay was carried out to verify the ability of the isolates in acting as inhibitors of mycelial growth, besides detecting the genes involved in the expression of polypeptides with antimicrobial action. In the greenhouse, the assay comprised of microbiolized seeds and addition of a suspension of propagules of each rhizobacteria to the soil at the moment of transplanting the tomato seedlings. All the rhizobateria isolates showed variable control levels of the pathogen in vitro. The UFG-07 and UFG-10 isolates, with high similarity with Bacillus subtilis and Bacillus circulans, excelled in the disease suppression. PCR results detected target genes for expression of polypeptides, what reinforces the hypothesis of action of antimicrobial substances in biocontrol.
\end{abstract}

KEY-WORDS: Fusarium oxysporum; Solanaceae; secondary metabolites.

\section{INTRODUÇÃO}

A cultura do tomate (Solanum lycopersicon L.) é acometida por diversas doenças de importância econômica. A murcha de fusário, causada por Fusarium oxysporum f. sp. lycopersici (Sacc.) Snyder \& Hansen (FOL), se destaca como uma das principais enfermidades da cultura (Reis \& Boiteux 2007).

O controle dessa doença fundamenta-se, principalmente, na introgressão de genes que expressam

\section{RESUMO}

Murchas vasculares em tomateiro constituem importante grupo de doenças incitadas por patógenos habitantes de solos, com destaque para Fusarium oxysporum f. sp. lycopersici, que ocasiona perdas significativas de produção. A introgressão de genes que expressam resistência é a principal medida de controle, mas, devido à rápida emergência de raças que suplantam a resistência, vem aumentando a importância do biocontrole, em integração com o controle genético. Objetivou-se avaliar a capacidade de isolados de rizobactérias, especialmente do gênero Bacillus, como agentes de biocontrole da murcha de fusário em tomateiro. O ensaio de laboratório consistiu na verificação da habilidade de os isolados atuarem como inibidores de crescimento micelial, além da detecção de genes envolvidos na expressão de polipeptídios de ação antimicrobiana. Em casa-de-vegetação, o ensaio foi composto por sementes microbiolizadas e adição, ao solo, de suspensão de propágulos de cada rizobactéria, no momento do transplantio das mudas de tomateiro. Todos os isolados de rizobactérias apresentaram controle variável do patógeno in vitro. Os isolados UFG-07 e UFG-10, com alta similaridade a Bacillus subtilis e Bacillus circulans, destacaram-se na supressão da doença. Resultados da PCR detectaram genes-alvo para expressão de polipeptídios, o que reforça a hipótese da ação de substâncias antimicrobianas no biocontrole.

PALAVRAS-CHAVE: Fusarium oxysporum; Solanaceae; metabólitos secundários.

resistência-específica às raças fisiológicas do patógeno e por meio de atividades biológicas associadas aos organismos antagonistas existentes no solo. Esses micro-organismos possuem a capacidade de limitar ou suprimir a ação de fitopatogênicos (Rocha \& Moura 2013).

Dentre os principais micro-organismos inseridos como agentes de biocontrole de doenças radiculares, em diversas culturas, encontram-se as espécies do gênero Bacillus ( $\mathrm{Li}$ et al. 2013). Esses procariotos possuem a capacidade de colonizar e se 
multiplicarem na rizosfera e/ou rizoplano de plantas cultivadas, onde podem atuar como antagonistas a fitopatógenos.

$\mathrm{O}$ antagonismo ocorre, principalmente, pela produção de diferentes polipeptídeos com ação antimicrobiana, como a mersacidina, micosubilitina, iturina, bacilomicina, fengicina, bacilicina e surfactina (Stein 2005), bem como por estimuladores de crescimento do hospedeiro (Tan et al. 2013). A inoculação desses agentes é uma alternativa viável, principalmente quando empregada em associação com outros métodos de controle, apresentando baixo custo e pouca agressividade ao ecossistema (Silva et al. 2004).

Atualmente, a prospecção e síntese de bioprodutos a partir de rizobactérias com ação de biocontrole estão em ascensão. Kavroulakis et al. (2010) confirmaram atividade antagonista de rizobactérias identificadas como Bacillus sp., Serratia marcescens e Enterobacter ludwigii, no biocontrole de F. oxysporum f. sp. radicis-lycopersici. Os autores indicaram as enzimas quitinase, $\beta$-glucanase e $\mathrm{HCN}$ como prováveis causadoras do antagonismo. Da mesma forma, Romeiro et al. (2010) investigaram a ação de metabólitos secundários de natureza proteica, produzidos por Bacillus cereus, na indução de resistência sistêmica a Corynespora cassiicola, em plantas de tomateiro. Zhao et al. (2013) utilizaram Bacillus subtilis, em combinação com fertilizante orgânico, e concluíram que a supressividade de Fusarium oxysporum f. sp. melonis ocorreu devido à formação de biofilme na rizosfera e rizoplano das plantas, que cria um ambiente hostil para o fitopatógeno. Além disso, a alta produção de lipopeptídeos com atividade antifúngica também contribuiu para o controle de Fusarium. Esse mecanismo foi também observado por Li et al. (2013), que utilizaram B. subtilis cepa HJ5 na supressão da murcha de verticílio, em algodoeiro.

Objetivou-se, com este estudo, avaliar (in vitro) a ação antagônica de rizobactérias do gênero Bacillus sp. sobre fitopatógenos da cultura do tomateiro e selecionar (in vivo) potenciais agentes de controle biológico da murcha de fusário do tomateiro, assim como elucidar os possíveis mecanismos envolvidos na supressão da doença.

\section{MATERIAL E MÉTODOS}

Os ensaios foram realizados em 2013 e 2014, na Universidade Federal de Goiás, em Goiânia (GO),
Brasil. Os isolados de rizobactérias foram obtidos por meio de isolamento de colônias bacterianas que se encontravam associadas (in vitro) a escleródios de Sclerotinia sclerotiorum, semeados em placas de Petri contendo meio BDA, inibindo, assim, a germinação do fungo. Utilizou-se o método de estrias em placas de Petri (Romeiro 2007) contendo meio de cultura 523 de Kado \& Heskett (1970), repicadas para tubos de ensaio codificados como UFG-01 a UFG-11 e preservados sob óleo mineral a $4{ }^{\circ} \mathrm{C}$ (Romeiro 2007). Esses isolados foram utilizados em ensaios experimentais in vitro e em casa-de-vegetação, como potenciais agentes antagonistas a Fusarium oxysporum f. sp. lycopersici (FOL).

Os isolados foram identificados pela análise de ésteres metílicos de ácidos graxos por cromatografia gasosa (GC-FAME), utilizando-se o sistema Sherlock ${ }^{\circledR}$ Microbial Identification System (TSBA40 library; MIDI Inc., Newark, DE, USA).

As rizobactérias empregadas como possíveis antagonistas foram cultivadas e multiplicadas em tubos de ensaio inclinados contendo meio 523 (Kado \& Heskett 1970) e incubadas em câmaras de crescimento por 48 horas, a $28{ }^{\circ} \mathrm{C}$. As suspensões bacterianas utilizadas tanto para os bioensaios in vitro quanto em casa-de-vegetação foram feitas com solução salina a $0,85 \%$ de $\mathrm{NaCl}$ e as concentrações ajustadas para $\mathrm{OD}_{540}=0,4$, com o auxílio de espectrofotômetro (Romeiro 2001), o que corresponde a, aproximadamente, $1 \times 10^{9} \mathrm{UFC} \mathrm{mL}^{-1}$. A solução salina esterilizada, empregada para ressuspensão dos isolados bacterianos, foi utilizada como controle.

Isolados das três raças de FOL constituíram o bioensaio in vitro e, em casa-de-vegetação, foi utilizado o isolado da raça 2 do patógeno. O preparo do inóculo proveio de três discos de $5 \mathrm{~mm}$ de diâmetro, contendo estrutura micelial do isolado, previamente cultivados durante 10 dias, em placa de Petri contendo meio BDA. Os discos foram depositados em frascos de Erlenmeyer contendo $250 \mathrm{~mL}$ de meio de cultura batata-dextrose (BD). Após 15 dias de crescimento em agitador automático a $25^{\circ} \mathrm{C}$ e iluminação contínua, a suspensão do inóculo foi filtrada em duas camadas de gaze esterilizada. A concentração de conídios foi aferida por meio de contagem em câmara de Neubauer, ajustando-a para 1 x $10^{6}$ microconídeos $\mathrm{mL}^{-1}$ (Souza et al. 2010).

A análise da capacidade de os antagonistas produzirem compostos antimicrobianos in vitro foi feita pelo método de antibiograma com discos de papel 
(Romeiro 2007), com modificações. Os propágulos de FOL foram previamente cultivados durante 10 dias, em placa de Petri contendo meio BDA. Sobre uma camada de $20 \mathrm{~mL}$ de meio BDA a $1,0 \%$, acrescido de $1 \mathrm{~mL}$ da suspensão de propágulos de FOL, foram pipetados $10 \mu \mathrm{L}$ de suspensão de cada isolado antagonista sobre um disco de papel (Quanty ${ }^{\circledR}$ ) de $0,5 \mathrm{~cm}$ de diâmetro, previamente autoclavado. Os discos de papel foram depositados equidistantemente na superfície do meio BDA. A antibiose foi determinada pela observação qualitativa da formação de halo de inibição do crescimento do fitopatógeno, após 72 horas de incubação a $28^{\circ} \mathrm{C}$.

Para averiguar a amplitude da antibiose das rizobactérias para outros fitopatógenos, o mesmo procedimento foi empregado utilizando-se Sclerotinia sclerotiorum, Alternaria solani, Corynespora cassiicola, Verticillium dahliae, Ralstonia solanacearum, Pseudomonas syringae pv. tomato, Pseudomonas corrugata, Xanthomonas campestris pv. campestris, Xanthomonas perforans e Clavibacter michiganensis subsp. michiganensis. Para as fitobactérias, foi utilizado meio 523 (Kado \& Heskett 1970) a 1,0 \%, acrescido de suspensão de propágulos de cada bactéria fitopatogênica previamente cultivada, durante 24 horas, em placas de Petri.

Para comprovar a atividade de metabólitos totais produzidos pelas rizobactérias, cada isolado foi incubado por 48 horas, a $28^{\circ} \mathrm{C}$, em três tipos de meio líquido de cultura: 523 , BD e solução salina $(0,85 \%$ de $\mathrm{NaCl})$. Após esse período, os filtrados de cada cultura foram preparados por centrifugação durante 30 minutos, a $4{ }^{\circ} \mathrm{C}$ e $12.000 \mathrm{~g}$, seguida de filtragem a vácuo, em membrana de nitrocelulose $0,2 \mu$ (Millipore $\left.^{\circledR}\right)$. O precipitado de rizobactérias foi utilizado para o método de antibiograma contra as raças fisiológicas de FOL. O meio de cultura sem propágulos de rizobactérias foi usado como controle.

Para aferir a atividade de produção de compostos voláteis capazes de interferir no crescimento das raças fisiológicas de FOL, foram utilizadas placas de Petri com $90 \mathrm{~mm}$ de diâmetro, divididas em dois compartimentos, conforme metodologia de placas sobrepostas descrita por Romeiro (2007), sendo que o primeiro compartimento de todas as placas foi preenchido com meio 523 (Kado \& Heskett 1970) e semeados, por espalhamento com alça de Drigalski, $50 \mu \mathrm{L}$ de suspensão de cada rizobactéria. Ao segundo compartimento foi adicionado meio BDA, no qual se depositou, no centro da placa, um disco de micélio do fitopatógeno com $5 \mathrm{~mm}$ de diâmetro. A testemunha constou, em um dos compartimentos de placas de Petri, somente do disco de micélio em meio BDA e, no outro compartimento, meio $523 \mathrm{sem}$ a presença de rizobactéria. Após seu preparo, as placas foram fechadas com Parafilm ' $M$ ' (Pechiney Plastic Packaging) e mantidas em BOD, a $28^{\circ} \mathrm{C}$, com fotoperíodo de 12 horas, por sete dias consecutivos.

$\mathrm{O}$ crescimento fúngico foi registrado no $7^{\circ} \mathrm{dia}$, pela medição do diâmetro da colônia sobre o eixo que liga os dois vértices da borda do compartimento. Para esse ensaio, a avaliação foi quantitativa e o arranjo experimental foi inteiramente casualizado, constituído de três repetições para cada tratamento. Os dados foram submetidos à análise de variância e as médias comparadas pelo teste Tukey, a $5 \%$, utilizando-se o programa estatístico Sisvar (Ferreira 2011).

$\mathrm{Na}$ avaliação do efeito das rizobactérias como agentes de biocontrole da murcha de fusário, em casa-de-vegetação, sementes de tomateiro (cv. 'Viradoro') foram microbiolizadas por embebição, por 24 horas, em suspensão de propágulos de cada rizobactéria (Moura et al. 1998, Silva et al. 2004), e colocadas para germinar em bandejas de poliestireno contendo substrato Plantmax ${ }^{\circledR}$ não autoclavado. Aos vinte dias após a semeadura, as mudas foram transplantadas para vasos com capacidade de 1,0 L, contendo solo areno-argiloso previamente autoclavado a $120^{\circ} \mathrm{C}$, por 40 minutos. Visando a colonizar a rizosfera do tomateiro, sete dias antes da inoculação do patógeno, $30 \mathrm{~mL}$ de suspensão de propágulos de cada rizobactéria foram adicionados a cada vaso, logo após o transplantio das mudas, com exceção do tratamento controle, em que foi adicionada solução salina. As plantas foram mantidas em casa-de-vegetação com temperatura média de $30^{\circ} \mathrm{C} \pm 7{ }^{\circ} \mathrm{C}$ e umidade relativa do ar de 40-70 \%. A inoculação do patógeno foi realizada aos 27 dias após a semeadura, pelo método de corte da raiz em meia lua (Gurgel et al. 2005), em que cada recipiente recebeu $30 \mathrm{~mL}$ de suspensão de conídios de FOL. O controle positivo consistiu de mudas advindas de sementes embebidas em solução salina, usada para ressuspender os isolados, e inoculadas com o patógeno. Já o controle negativo constituiu-se de plantas com raízes cortadas e sem a presença de conídios do patógeno.

O resultado consistiu de uma única avaliação da severidade da doença aos 23 dias após a inoculação, utilizando-se uma escala de notas adaptada por Santos (1997), onde: 1 = planta sem sintomas; 
2 = planta sem sintomas de murcha e apresentando pequena descoloração vascular; 3 = planta com sintomas de murcha e descoloração vascular; 4 = planta com severa murcha associada à presença de clorose e necrose foliar; $5=$ planta morta. Após o cálculo da média de notas de cada tratamento, essas foram agrupadas em três classes de reações propostas por Dordevic et al. (2012), como se segue: 1,0-2,0 = resistentes, ou seja, com supressão da doença; 2,1-3,0 = moderadamente resistentes, com supressão parcial da doença; 3,1-5,0 = suscetível, não houve controle.

O delineamento experimental foi inteiramente casualizado, consistindo de 13 tratamentos com dez repetições, sendo cada repetição constituída por um vaso com duas plantas. Os dados foram submetidos à análise de variância e as médias comparadas pelo teste Tukey, a $1 \%$, utilizando-se o programa estatístico Sisvar (Ferreira 2011).

A detecção por PCR de genes biosintetizantes de substâncias antimicrobianas foi feita pela suspensão de cada rizobactéria, centrifugada por 30 minutos a $12.000 \mathrm{~g}$, com descarte do sobrenadante. O precipitado foi utilizado para a extração do DNA genômico, pelo método CTAB $2 \mathrm{X}$, como descrito por Boiteux et al. (1999), e quantificado em espectrofotômetro. O marcador ITUD [5'-TTG-AAY-GTC-AGY-GCS-CCT-TT-3' e 5'-TGC-GMA-AAT-AAT-GGS-GTC-GT-3'] foi utilizado para detectar simultaneamente os genes bamD, ituD e $f e n F$, pertencentes à região genômica conservada, que codifica malonil-CoA transacilase, envolvida na biossíntese de bacillomicina-D, iturina e micosubilitina, respectivamente. Os marcadores BACAB [5'-CTT-CTC-CAA-GGG-GTG-AAC-AG-3' e 5'-TGT-AGG-TTT-CAC-CGG-CTT-TC-3'], MRSA [5'-GGG-TAT-ATG-CGG-TAT-AAA-CTT-ATG-3' e 5'-GTT-TCC-CCA-ATG-ATT-TAC-CCT-C-3'] e SFP [5'-ATG-AAG-ATT-TAC-GGA-ATT-TA-3' e 5'-TTA-TAA-AAG-CTC-TTC-GTA-CG-3'] foram utilizados para amplificar as regiões genômicas específicas, identificadas como genes bacAB, $m r s A$ e $s f P$, que expressam bacilisina, mersacidina e surfactina, respectivamente (Chung et al. 2008).

Para cada reação de PCR, foram utilizados $5.0 \mu 1$ de Premix 2X (EmeraldAmp ${ }^{\circledR}$ GT PCR Master Mix), $2.0 \mu 1$ DNA a $10 \mathrm{ng} / \mu 1,0.3 \mu 1$ dos oligonucleotídeos iniciadores ajustados a 2.5 pM e água ultrapura, para completar o volume final de $12 \mu \mathrm{l}$. A amplificação foi realizada em termociclador Biocycler (Biosystem ${ }^{\circledR}$ ) e seguiu o protocolo proposto por Chung et al. (2008), com modificações. As etapas da reação foram desnaturação a $95^{\circ} \mathrm{C}$, por 1 minuto, e 40 ciclos compostos de $95{ }^{\circ} \mathrm{C}$ por 30 segundos; $54{ }^{\circ} \mathrm{C}$ por 45 segundos, para anelamento dos oligonucleotídeos iniciadores; e $72{ }^{\circ} \mathrm{C}$ por 45 segundos, para extensão. Finalizados os ciclos, procedeu-se a uma extenção final a $72{ }^{\circ} \mathrm{C}$, por 5 minutos. Todos os produtos de PCR foram separados por eletroforese a $80 \mathrm{~V}$, utilizando-se gel de agarose $1,5 \%$ pré-fundido em tampão TBE contendo GelRed, e visualizados em translaminador UV.

\section{RESULTADOS E DISCUSSÃO}

Os resultados da taxonomia mostraram que todos os isolados submetidos à identificação por análise de ésteres metílicos de ácidos graxos (GC-FAME) foram identificados como pertencentes ao gênero Bacillus sp. Os isolados UFG-01 a UFG-06 tiveram alta similaridade com a espécie Bacillus subtilis subsp. spizizenii, os isolados UFG-07, UFG-08 e UFG-11 com Bacillus subtilis e UFG-09 e UFG-10 com Bacillus circulans.

Representantes da espécie Bacillus subtilis são conhecidos por produzirem diversos lipopeptídios de características biológicas com atividades antimicrobianas, como surfactina, fengicina, iturina, mersacidina e bacilomicina (Chung et al. 2008), enquanto os isolados de Bacillus circulans produzem circulocina, que apresenta ação antibiótica em bactérias Gram positivas (He et al. 2001). Essas duas espécies, frequentemente, são relatadas como agentes promotores de crescimento de plantas (Kumar et al. 2012), indutores de resistência (Pieterse et al. 2014) e agentes de biocontrole de fitopatógenos ( $\mathrm{Li}$ et al. 2012, Zhao et al. 2013).

A atividade antimicrobiana desses isolados foi confirmada pela observação da efetividade na inibição do crescimento de propágulos de fitopatógenos fúngicos e um bacteriano, in vitro (Tabela 1). Esses resultados estão em consonância com outros relatos sobre a existência de substâncias antibióticas e antifúngicas produzidas por espécies de Bacillus contra fungos, bactérias e até nematoides fitopatogênicos (He et al. 2001, Chung et al. 2008, Ayeda et al. 2014). As avaliações qualitativas tiveram o intuito de averiguar a produção de compostos antimicrobianos pelas rizobactérias (Vieira et al. 2015).

Todos os isolados de Bacillus apresentaram atividade de inibição de crescimento micelial in vitro às 
três raças fisiológicas de FOL, por meio de compostos não voláteis. A capacidade de cada rizobactéria inibir o crescimento micelial do patógeno, pelo método de antibiose com filtrado de metabólitos totais, foi influenciada pelo meio de crescimento utilizado (Tabela 2). Esse resultado indica que a habilidade de produção de metabólitos secundários é dependente da expressão gênica mediada por diferentes fatores físicos, químicos e biológicos, como o tipo de meio de cultivo utilizado para o seu desenvolvimento (Vieira et al. 2015).

Ao avaliar a interferência dos isolados de Bacillus na inibição micelial de FOL por compostos voláteis (Tabela 2), as rizobactérias apresentaram comportamento variável, quanto à capacidade de inibir o crescimento das diferentes raças do patógeno. Essas observações sugerem diferenças na quantidade

Tabela 1. Inibição (in vitro) de propágulos de fitopatógenos, constatada pela formação de halo de inibição ao redor da suspensão de cada isolado de rizobactéria (Goiânia, GO, 2013).

\begin{tabular}{|c|c|c|c|c|c|c|c|c|c|c|c|}
\hline \multirow{2}{*}{ Fitopatógenos } & \multicolumn{11}{|c|}{ Bacillus sp. } \\
\hline & UFG-01 & UFG-02 & UFG-03 & UFG-04 & UFG-05 & UFG-06 & UFG-07 & UFG-08 & UFG-09 & UFG-10 & UFG-11 \\
\hline Sclerotinia sclerotiorum & + & + & + & + & + & + & + & + & + & + & + \\
\hline Alternaria solani & + & + & + & + & + & + & + & + & + & + & + \\
\hline Corynespora cassiicola & + & + & + & + & + & + & + & + & + & + & + \\
\hline Verticillium dahliae & + & + & + & + & + & + & + & + & + & + & + \\
\hline $\begin{array}{l}\text { Fusarium oxysporum f. sp. } \\
\text { lycopersici }\end{array}$ & + & + & + & + & + & + & + & + & + & + & + \\
\hline Ralstonia solanacearum & - & - & - & - & - & - & - & - & - & - & - \\
\hline $\begin{array}{l}\text { Pseudomonas syringae pv. } \\
\text { tomato }\end{array}$ & - & - & - & - & - & - & - & - & - & - & - \\
\hline Pseudomonas corrugata & - & - & - & - & - & - & - & - & - & - & - \\
\hline $\begin{array}{l}\text { Xanthomonas campestris } \\
\text { pv. campestris }\end{array}$ & - & - & - & - & - & - & - & - & - & - & - \\
\hline Xanthomonas perforans & - & - & - & - & - & - & - & - & - & - & - \\
\hline $\begin{array}{l}\text { Clavibacter michiganensis } \\
\text { subsp. michiganensis }\end{array}$ & + & + & + & + & + & + & + & + & + & + & + \\
\hline Controle & - & - & - & - & - & - & - & - & - & - & - \\
\hline
\end{tabular}

$+=$ presença de halo de inibição; - = ausência de halo.

Tabela 2. Inibição de crescimento micelial de Fusarium oxysporum f. sp. lycopersici, por meio dos métodos de antibiograma com suspensão de propágulos e produção de metabólitos totais de cada rizobactéria, em diferentes meios de crescimento, e por compostos voláteis, pelo método de placas sobrepostas (Goiânia, GO, 2013).

\begin{tabular}{|c|c|c|c|c|c|c|c|c|c|c|c|c|c|c|c|}
\hline \multirow{3}{*}{ Isolados } & \multirow{2}{*}{\multicolumn{3}{|c|}{$\begin{array}{l}\text { Suspensão } \\
\text { antagonista }\end{array}$}} & \multicolumn{9}{|c|}{ Metabólitos totais } & \multirow{2}{*}{\multicolumn{3}{|c|}{$\begin{array}{c}\text { Compostos voláteis } \\
\text { Diâmetro da colônia }(\mathrm{mm})\end{array}$}} \\
\hline & & & & \multicolumn{3}{|c|}{ Meio 523} & \multicolumn{3}{|c|}{ Meio BD } & \multicolumn{3}{|c|}{ Solução salina } & & & \\
\hline & $\mathrm{r} 1^{1}$ & $\mathrm{r} 2$ & r3 & $\mathrm{r} 1$ & $\mathrm{r} 2$ & $\mathrm{r} 3$ & $\mathrm{r} 1$ & $\mathrm{r} 2$ & r3 & $\mathrm{r} 1$ & $\mathrm{r} 2$ & r3 & $\mathrm{r} 1$ & $\mathrm{r} 2$ & r3 \\
\hline UFG-01 & $+^{2}$ & + & + & - & - & - & + & + & + & - & - & - & $73,3 \mathrm{e}^{3}$ & $73,0 \mathrm{~cd}$ & $64,3 \mathrm{~d}$ \\
\hline UFG-02 & + & + & + & - & - & - & + & + & + & - & - & - & $74,7 \mathrm{e}$ & $76,0 \mathrm{~d}$ & $74,3 \mathrm{e}$ \\
\hline UFG-03 & + & + & + & - & - & - & + & + & + & - & - & - & $53,0 \mathrm{a}$ & $79,3 \mathrm{~d}$ & $72,7 \mathrm{e}$ \\
\hline UFG-04 & + & + & + & - & - & - & + & + & + & - & - & - & $63,7 \mathrm{~cd}$ & $74,3 \mathrm{~d}$ & $52,3 \mathrm{c}$ \\
\hline UFG-05 & + & + & + & - & - & - & + & + & + & - & - & - & $49,0 \mathrm{a}$ & $63,0 \mathrm{ab}$ & $63,7 \mathrm{~d}$ \\
\hline UFG-06 & + & + & + & - & - & - & + & + & + & - & - & - & $72,0 \mathrm{e}$ & $65,3 \mathrm{~b}$ & $52,7 \mathrm{c}$ \\
\hline UFG-07 & + & + & + & - & - & - & + & + & + & - & - & - & $54,3 \mathrm{ab}$ & $57,7 \mathrm{a}$ & $23,7 \mathrm{a}$ \\
\hline UFG-08 & + & + & + & - & - & - & + & + & + & - & - & - & $72,0 \mathrm{c}$ & $74,7 \mathrm{~d}$ & $73,0 \mathrm{e}$ \\
\hline UFG-09 & + & + & + & - & - & - & + & + & + & - & - & - & $70,7 \mathrm{de}$ & $60,0 \mathrm{ab}$ & $37,0 \mathrm{~b}$ \\
\hline UFG-10 & + & + & + & - & - & - & + & + & + & - & - & - & $70,3 \mathrm{de}$ & $66,3 \mathrm{bc}$ & $39,3 \mathrm{~b}$ \\
\hline UFG-11 & + & + & + & - & - & - & + & + & + & - & - & - & $62,7 \mathrm{bc}$ & $65,7 \mathrm{~b}$ & $62,7 \mathrm{~d}$ \\
\hline Controle & - & - & - & - & - & - & - & - & - & - & - & - & $90,0 \mathrm{f}$ & $75,7 \mathrm{~d}$ & $74,3 \mathrm{e}$ \\
\hline CV (\%) & & & & & & & & & & & & & 3,26 & 4,39 & 4,44 \\
\hline
\end{tabular}

${ }^{1}$ r1, r2 e r3 = Fusarium oxysporum f. sp. lycopersici raças 1,2 e 3 , respectivamente ${ }^{2}+=$ presença de halo de inibição; $-=$ ausência de halo. ${ }^{3}$ Colunas seguidas da mesma letra não diferem estatisticamente entre si, a $5 \%$, pelo teste Tukey. 
e/ou proporção dos distintos metabólitos voláteis produzidos pelos isolados bacterianos. $\mathrm{O}$ isolado UFG-07 apresentou maior homogeneidade na restrição do crescimento das raças 1, 2 e 3 de FOL, com, aproximadamente, $39,63 \%, 23,80 \%$ e $68,15 \%$ de controle do crescimento micelial, respectivamente, em relação à testemunha.

A técnica da PCR foi utilizada para detectar genes possivelmente envolvidos na biossíntese de substâncias antimicrobianas. Esses genes foram previamente descritos em Bacillus sp. (Stein 2005). Os produtos de amplificação de tamanho esperado, obtidos com os oligonucleotídeos iniciadores ITUD e BACAB, foram confirmados, exceto para o isolado UFG-08, que não apresentou produto de amplificação com os primers ITUD, e para os isolados UFG-01, 02 e 03, que não apresentaram produto de amplificação com os primers BACAB. Esses oligonucleotídeos iniciadores são usados para detectar genes envolvidos na biossíntese de bacilomicina $\mathrm{D}$, iturina e micosubilitina, via rota não-ribossomal, e de bacilicina, via rota ribossomal (Figura 1). Os genes-alvo envolvidos na biossíntese de mersacidina e surfactina não foram detectados, provavelmente devido a possíveis substituições e/ou inserções de bases no gene $s f P$, reportado para alguns isolados de Bacillus sp. produtores parciais dessas substâncias (Li et al. 2012).

A constatação de genes envolvidos na expressão de lipopeptídeos produzidos pelos isolados corrobora os resultados da inibição de crescimento de fitopatógenos em condições gnotobióticas (Tabela 1), em que foram observadas atividades antifúngicas em ampla gama de patógenos, ainda que com atividade antibacteriana limitada. A expressão desses genes pode ser utilizada pelos antagonistas para adaptação e sobrevivência, à medida que fornecem vantagem competitiva contra fitopatógenos sensíveis a esses compostos, podendo, com isso, suprimir as doenças (Ayeda et al. 2014).

No ensaio em casa-de-vegetação, visando à supressão da murcha de fusário em tomateiro, as rizobactérias UFG-01, UFG-06, UFG-07, UFG-10 e UFG-11 diferiram estatisticamente na redução à severidade da doença, quando comparadas ao controle (Figura 2). Entretanto, somente os isolados UFG-07 e UFG-10 apresentaram reação à doença com índices inferiores à nota 2 , ou seja, plantas tratadas com essas rizobactérias proporcionaram supressão da murcha de fusário pela redução de sintomas avaliados aos 23 dias após a inoculação, quando comparadas com o tratamento controle. A redução na intensidade da doença permitiu selecionar os isolados UFG-07 (B. subtilis) e UFG-10 (B. circulans) como potenciais agentes de biocontrole da murcha de fusário do tomateiro. Resultados obtidos neste trabalho indicam que essas rizobactérias podem atuar por diferentes mecanismos de ação, como antibiose por metabólitos voláteis e não voláteis, e, inclusive, pela

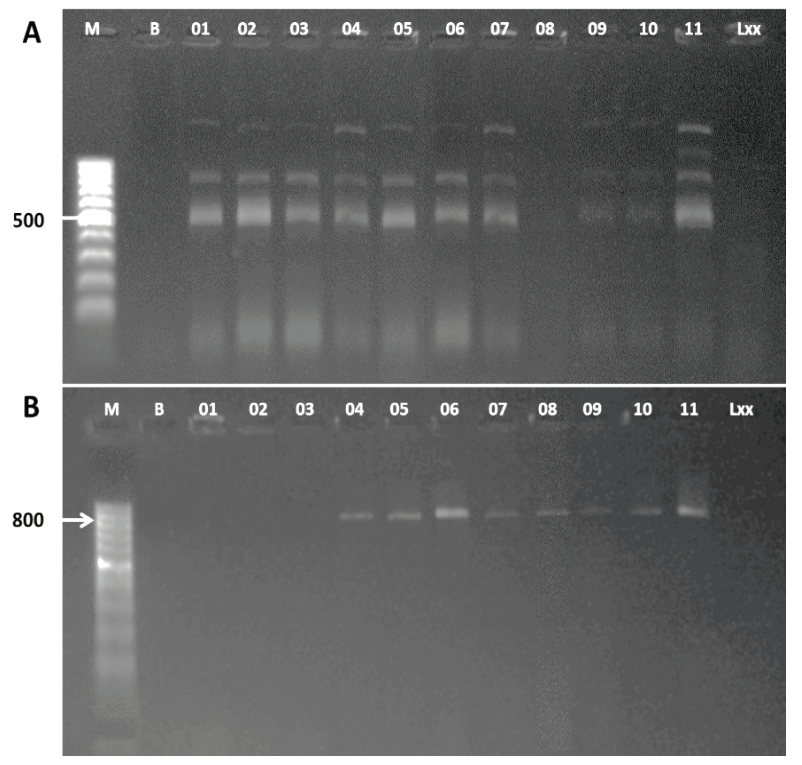

Figura 1. Produtos da amplificação da PCR em gel de agarose $1,5 \%$ obtido com o uso dos pares de oligonucleotídeos iniciadores ITUD (A) e BACAB (B) (Goiânia, GO, 2014). Os ensaios da PCR foram realizados utilizandose DNA genômico extraído de cada isolado de Bacillus sp. Detecção de genes-alvo para iturina $(i t u D)$ e bacilicina $(b a c D)$ mostram alelos com tamanho de, aproximadamente, $500 \mathrm{pb}$ e $800 \mathrm{pb}$, respectivamente. $\mathrm{M}=$ marcador $100 \mathrm{pb} ; \mathrm{B}=$ controle com água; 1 a $11=$ UFG-01 a UFG-11.

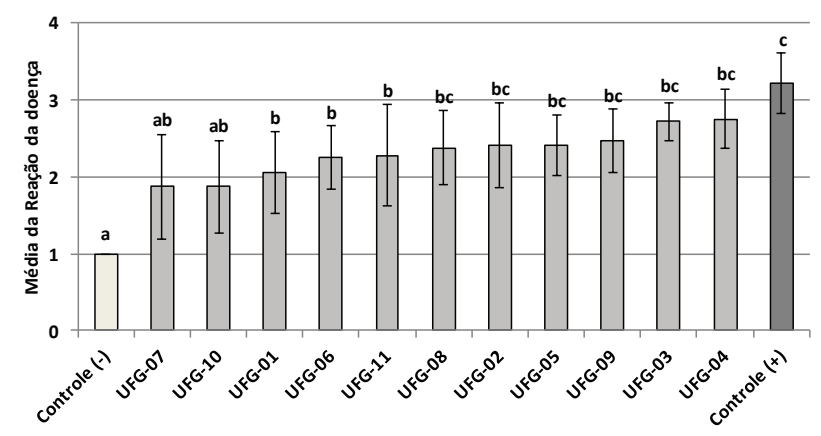

Figura 2. Nível de severidade da murcha de fusário em tomateiros inoculados com isolados de Bacillus sp. (Goiânia, GO, 2014). Médias seguidas pela mesma letra não diferem entre si, a $1 \%$, pelo teste Tukey. 
possibilidade de ocorrência de efeitos sinergísticos entre os lipopeptídeos produzidos, o que amplia as possibilidades de sobrevivência, adaptação e controle de uma ampla gama de fitopatógenos.

Os isolados UFG-07 e UFG-10 de Bacillus sp. despontaram como potenciais micro-organismos a serem utilizados no manejo integrado da murcha de fusário em tomateiro. Esse biocontrole poderá ser ampliado pelo desenvolvimento de novas estratégias, como a combinação com múltiplos agentes de biocontrole (Souza Júnior et al. 2010), rotação com controle químico (Silva et al. 2004) e redução da pressão de inóculo inicial ou aumento da supressividade de solos a fitomoléstias, além de influenciar na diminuição de possíveis emergências de raças patogênicas (Chung et al. 2008).

\section{CONCLUSÕES}

1. Os isolados identificados como Bacillus sp. produzem, in vitro, substâncias solúveis com ação inibitória ao crescimento de propágulos de S. sclerotiorum, A. solani, C. cassiicola, V. dahliae, C. m. michiganensis e das três raças fisiológicas de Fusarium oxysporum f. sp. lycopersici.

2. As rizobacterias $B$. subtilis-UFG-07 e B. circulans-UFG-10 exercem, em casa-de-vegetação, supressão da doença incitada por Fusarium oxysporum f. sp. lycopersici. Esses isolados produzem substâncias voláteis e não voláteis solúveis, com ação inibitória ao crescimento micelial do patógeno.

3. Os genes envolvidos na biossíntese de bacilomicina $\mathrm{D}$, iturina, micosubilitina e bacilicina foram amplificados na maioria dos isolados e, portanto, podem estar envolvidos na ação antibiótica desses Bacillus.

\section{REFERÊNCIAS}

AYEDA, H. B. et al. Identification and biochemical characteristics of lipopeptides from Bacillus mojavensis A21. Process Biochemistry, Amsterdam, v. 49, n. 1, p. 1699-1707, 2014.

BOITEUX, L. S.; FONSECA, M. E. N.; SIMON, P. W. Effects of plant tissue and DNA purification method on RAPD-based genetic fingerprinting analysis in carrot. Journal of the American Society of Horticultural Science, Alexandria, v. 124, n. 1, p. 32-38, 1999.

CHUNG, S. et al. Isolation and partial characterization of Bacillus subtilis ME488 for suppression of soilborne pathogens of cucumber and pepper. Applied Microbial Biotechnology, Berlin, v. 80, n. 1, p. 115-123, 2008.

DORDEVIC, M. et al. Reaction of different tomato cultivars toward race 1 of Fusarium oxysporum f. sp. lycopersici. Genetika, Zemum, v. 44, n. 1, p. 109-118, 2012.

FERREIRA, D. F. Sisvar: a computer statistical analysis system. Ciência e Agrotecnologia, Lavras, v. 35, n. 6, p. 1039-1042, 2011.

GURGEL, L. M. S. et al. Proteção à murcha de fusário do tomateiro com acibenzolar-smetil e ácido $\beta$-aminobutírico, em campo. Fitopatologia Brasileira, Brasília, DF, v. 30, n. 6, p. 655-657, 2005.

HE, H. et al. Circulocins, new antibacterial lipopeptides from Bacillus circulans, J2154. Tetrahedron, Oxford, v. 57, n. 7, p. 1189-1195, 2001.

KADO, C. I.; HESKETT, M. G. Selective media for isolation of Agrobacterium, Corynebacterium, Erwinia, Pseudomonas and Xanthomonas. Phytopathology, Saint Paul, v. 60, n. 1, p. 969-979, 1970.

KAVROULAKIS, N. et al. Antagonistic bacteria of composted agro-industrial residues exhibit antibiosis against soil-borne fungal plant pathogens and protection of tomato plants from Fusarium oxysporum $\mathrm{f}$. sp. radicislycopersici. Plant Soil, Saint Paul, v. 333, n. 2, p. 233-247, 2010.

KUMAR, P.; DUBEY, R. C.; MAHESHWARI, D. K. Bacillus strains isolated from rhizosphere showed plant growth promoting and antagonistic activity against phytopathogens. Microbiological Research, Bethesda, v. 167, n. 8, p. 493-499, 2012.

LI, L. et al. Screening and partial characterization of Bacillus with potential applications in biocontrol of cucumber Fusarium wilt. Crop Protection, Amsterdam, v. 35, n. 1, p. 29-35, 2012.

LI, S. et al. Antagonist Bacillus subtilis HJ5 controls Verticillium wilt of cotton by root colonization and biofilm formation. Biology Fertility Soils, Berlin, v. 49, n. 1, p. 295-303, 2013.

MOURA, A. B.; ROMEIRO, R. S.; NEVES, M. C. P. Bioensaio para avaliação massal de actinomicetos antagonistas a Ralstonia solanacearum em tomateiro. Pesquisa Agropecuária Brasileira, Brasília, DF, v. 33, n. 12, p. 2065-2072, 1998.

PIETERSE, C. M. J. et al. Induced systemic resistance by beneficial microbes. Annual Review Phytopathology, Palo Alto, v. 52, n. 16, p. 347-375, 2014.

REIS, A.; BOITEUX, L. S. Outbreak of Fusarium oxysporum f. sp. lycopersici race 3 in commercial fresh- 
market tomato fields in Rio de Janeiro State, Brazil. Horticultura Brasileira, Brasília, DF, v. 25, n. 3, p. 451454, 2007.

ROCHA, D. J. A.; MOURA, A. B. Controle biológico da murcha de tomateiro causada por Ralstonia solanacearum e Fusarium oxysporum f. sp. licopersici por rizobactérias. Tropical Plant Pathology, Brasília, DF, v. 38, n. 5, p. 423430, 2013.

ROMEIRO, R. S. Controle biológico de doenças de plantas: procedimentos. Viçosa: UFV, 2007.

ROMEIRO, R. S. Métodos em bacteriologia de plantas. Viçosa: UFV, 2001.

ROMEIRO, R. S. et al. Evidence that the biocontrol agent Bacillus cereus synthesizes protein that can elicit increased resistance of tomato leaves to Corynespora cassiicola. Tropical Plant Pathology, Brasília, DF, v. 35, n. 1, p. 11-15, 2010.

SANTOS, J. R. M. Methodology for screening tomato for Fusarium wilt, Verticillium wilt, gray leaf spot, early blight and Septoria leaf blight. Recife: IPA, 1997.

SILVA, H. S. A. et al. Induction of systemic resistance by Bacillus cereus against tomato foliar diseases under field conditions. Journal of Phytopathology, Berlin, v. 152, n. 6 , p. 371-375, 2004.
SOUZA JÚNIOR, I. T. et al. Biocontrole da queima das bainhas e do nematoide das galhas e promoção de crescimento de plantas de arroz por rizobactérias. Pesquisa Agropecuária Brasileira, Brasília, DF, v. 45, n. 11, p. 12591267, 2010.

SOUZA, L. T. et al. Reação de genótipos de tomateiro às raças 2 e 3 de Fusarium oxysporum f. sp. lycopersici. Horticultura Brasileira, Brasília, DF, v. 28, n. 1, p. 102106, 2010.

STEIN, T. Bacillus subtilis antibiotics: structures, syntheses and specific functions. Molecular Microbiology, Oxford, v. 56, n. 4, p. 845-857, 2005.

TAN, S. et al. The effect of organic acids from tomato root exudates on rhizosphere colonization of Bacillus amyloliquefaciens T-5. Applied Soil Ecology, Amsterdam, v. 64 , n. 1, p. 15-22, 2013.

VIEIRA, B. A. H. et al. Understanding the mechanism of biological control of passion fruit bacterial blight promoted by autochthonous phylloplane bacteria. Biological Control, San Diego, v. 80, n. 4, p. 40-49, 2015.

ZHAO, Q. et al. Biocontrol of Fusarium wilt disease in muskmelon with Bacillus subtilis Y-IVI. BioControl, Amsterdam, v. 58, n. 2, p. 283-292, 2013. 